\title{
A Rectangular Microstrip Patch Antenna for Wireless Communications Operates in Dual Band
}

\author{
Sheikh Dobir Hossain ${ }^{\mathrm{a}}$, K. M. Abdus Sobahan ${ }^{\mathrm{b}}$, Md. Khalid Hossain ${ }^{\mathrm{c}^{*}}$, Md. Masud Ahamed \\ Akash $^{\mathrm{d}}$, Rebeka Sultana ${ }^{\mathrm{e}}, \mathrm{Md}$. Masum Billah ${ }^{\mathrm{f}}$ \\ ${ }^{a, f}$ Dept. of Physics, Jessore University of Science and Technology, Jessore-7408, Bangladesh \\ ${ }^{b, d}$ Dept. of Applied Physics, Electronics \& Communication Engineering, Islamic University, Bangladesh \\ ${ }^{c}$ Institute of Electronics, Atomic Energy Research Establishment, Savar, Dhaka, Bangladesh \\ ${ }^{e}$ Department of Electrical and Electronic Engineering, Shizuoka University, Shizuoka, Japan
}

\begin{abstract}
A single layer substrate compact dual band rectangular micro-strip patch antenna with transmission line feeding is designed for Wireless Local Area Networks (WLAN) implementation. The desired antenna consists of a rectangular patch having two I-slots and a dielectric material with dielectric constant of 2.4. The use of cavity model with transmission line feed has the favor of low profile, high gain and wide bandwidth of the antenna. The antenna has overall size of $46.9 \mathrm{~mm}$ by $38.01 \mathrm{~mm}$ and gives bandwidth of about $90 \mathrm{MHz}$ at resonance frequency of $2.45 \mathrm{GHz}$ and that of $115 \mathrm{MHz}$ at $4.1 \mathrm{GHz}$ frequency with Defected Ground Structure (DGS). The antenna with DGS has return losses $-21.25 \mathrm{~dB}$ at $2.45 \mathrm{GHz}$ and $-27.5 \mathrm{~dB}$ at $4.1 \mathrm{GHz}$ where the gains are 6.70 $\mathrm{dB}$ for $2.45 \mathrm{GHz}$ and $6.80 \mathrm{~dB}$ for $4.1 \mathrm{GHz}$. Finally the designed antenna has been simulated using Computer Simulation Technology (CST) microwave studio 2009 and it is comparable with manual computation results which are found to be suitable for WLAN applications.
\end{abstract}

Index Terms: Micro-strip antenna; Cavity model; Dual band antenna; Coaxial probe feed.

(C) 2016 Published by MECS Publisher. Selection and/or peer review under responsibility of the Research Association of Modern Education and Computer Science

\section{Introduction}

The wireless communication system has been developed rapidly in the past decades and it has already a dramatic impact on human life. In the last few years, the development of wireless local area networks (WLAN) represented one of the principal interests in the information and communication field. Thus, in commercial and government communication systems, it is required to develop low cost, minimal weight and low profile antennas that are capable of maintaining high performance over a large spectrum of frequencies.

* Corresponding author

E-mail address: khalid.baec@yahoo.com 
This technological trend has focused on the design of micro-strip antennas with a simple geometry. Patch antennas offer many advantages that are not commonly exhibited in any other types of antenna configurations. Microstrip antennas are simple and inexpensive to fabricate using printed circuit board technology. They have extremely low profile and light weight [1]-[2]. They are compatible with microwave and millimeter-wave integrated circuits, and have the ability to conform to planar and non-planar surfaces. In addition, once the shape and operating mode of the patch are selected, designs become very versatile in terms of operating frequency, polarization pattern and impedance. The lower efficiency, higher value of $\mathrm{Q}$, poor polarization purity, poor scan performance, spurious feed radiation and very narrow frequency bandwidth of a microstrip patch antenna have reduced their versatility. But in some applications where narrow bandwidth is desirable such as government security system the microstrip patch antenna are undeniable [3].

However the larger bandwidth (as long as 90 percent) and good efficiency (up to about 35 percent) of the desired microstrip antenna can be achieved by increasing the thickness of the dielectric materials [4]. But when the height of the dielectric substance increases then there some power losses occur due to surface wave [5]-[6]. However there are some methods such as cavity method and stacking as well as other method are used to reduce the surface wave and hence the power losses while sustaining the large bandwidth and good efficiency [7]. Also both linear and circular polarization of a rectangular microstrip patch antenna has increased their versatility.

\section{Literature Review}

Before the revolution (i.e. 1970) of electronic circuit miniaturization and large-scale integration in wireless communication the microstrip antenna (MSA) with conducting patch on a ground substrate was undeveloped. After that the radiations from radiating patch of a microstrip antenna with different configuration have been studied by many researchers. A low profile flush mounted microstrip antenna was the early work of Munson for the applications of rocket and missile practically. Gradually because of high demand in communication the multiband frequency modes operation can be obtained by using multilayer structures. To increase the fields of this antenna the various mathematical models were also developed. The last ten years papers or articles published in journals on these antennas show the importance gained by them. It is the most favorite choice to design micro strip antennas for the present day antenna designer's [8]. The literature survey on microstrip antenna has discussed in this section.

A couple line feed in a rectangular patch antenna is described by Van et al. [9]. The larger bandwidth antenna is obtained which is more than by a factor 2.5 than the normal edge fed patch antenna. Also the low physical dimension antenna is achieved over the previously available research while maintain their larger output. Chiba et al. introduced a dual-frequency planar antenna for handsets. The author has described an outer quarter-wavelength annular-ring with a short-circuited plane for a low resonance frequency and for high frequency response an inner quarter-wave length rectangular patch of a dual-band antenna [10]. Mark et al. proposed a L probe feed rectangular microstrip patch antenna for WLAN applications [11]. In this paper the author attains $36 \%$ impedance bandwidth and about 7-dBi average gain by introducing the attractive L shaped probe feed for the thick microstrip antenna. A U-slot rectangular patch on the substrate layer has been presented by Tong et al. [12]. Here due to the design of a broad-band -slot patch antenna on a microwave substrate the thickness of the desired antenna has increased than the case with a foam material. But the measured resonant frequencies and far-field patterns are well suited than the previous measured data and the gain of the desired antenna is about $6.5 \mathrm{~dB}$. The authors have used a U-slot circular patch antenna with L-probe feeding and also there has been used foam substrate which is presented by Guo et al. in. Hence there obtained a larger bandwidth i.e. about $15 \%$ than that using the U-slot alone and about $14 \%$ than that using the L-probe alone [13]. 


\section{Experimental Model}

The geometry of the designed dual band rectangular micro-strip patch antenna using CST 2009 is shown in Fig.1. The designed dual band antenna operates at the resonant frequency of $2.76 \mathrm{GHz}$ and $5.9 \mathrm{GHz}$. Due to the easy of fabrication and good impedance matching here we have used transmission line feeding technique. The thickness of substrate are taken between $.003 \lambda_{\mathrm{o}}<\mathrm{h}<.05$ in order to achieve maximum bandwidth [14].

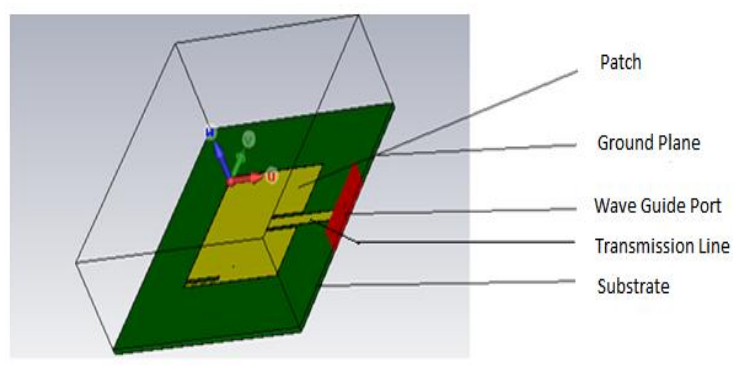

Fig.1. Geometry of dual band MSA

The very popular and practical approximate for different parameter of rectangular microstrip patch antenna are [15]

The width that's leads to good radiation efficiencies is

$w=\frac{v_{0}}{2 f_{r}} \times \sqrt{\frac{2}{\varepsilon_{r}+1}}$

Here,

$$
\begin{gathered}
v_{0}=\text { Velocity of light }=300 \times 10^{9} \mathrm{~mm} / \mathrm{sec} \\
f_{r}=\text { Resonant frequency } \\
\varepsilon_{r}=\text { Dielectric constant of the substrate }
\end{gathered}
$$

The value of effective dielectric constant is

$\varepsilon_{\text {reff }}=\frac{\varepsilon_{r}+1}{2}+\frac{\varepsilon_{r}-1}{2 \sqrt{1+\frac{12 h}{W}}}$

Where, $\mathrm{h}$ is the thickness of the substrate and must be in $\mathrm{mm}$ unit

The normalized extension of the length is

$$
\frac{\Delta L_{e f f}}{h}=0.412 \frac{\left(\varepsilon_{r e f f}+0.3\right)\left(\frac{W}{h}+0.264\right)}{\left(\varepsilon_{r e f f}-0.258\right)\left(\frac{W}{h}+0.8\right)}
$$

The effective length of the patch is

$$
L_{e f f}=\left(L+2 \Delta L_{e f f}\right)
$$


Where actual length is

$L=\frac{v_{0}}{2 f_{r} \sqrt{\varepsilon_{\text {reff }}}}-2 \Delta L$

\section{Antenna Designed Specification}

The different parameters of our designed dual band rectangular microstrip antenna are shown in table 1.

Table 1. Various parameter of dual-band rectangular microstrip antenna

\begin{tabular}{ll}
\hline Parameters & Values \\
\hline Length of the Patch $(\mathrm{Lp})$ & $38.01 \mathrm{~mm}$ \\
Width of the Patch $(\mathrm{Wp})$ & $46.9 \mathrm{~mm}$ \\
Dielectric constant of the Patch $\left(\varepsilon_{\mathrm{r}}\right)$ & 2.40 \\
Inset depth of the Patch $\left(\mathrm{Y}_{0}\right)$ & $13 \mathrm{~mm}$ \\
Width of the Microstrip line $\left(\mathrm{W}_{\mathrm{f}}\right)$ & $4.2 \mathrm{~mm}$ \\
Width of the slots $\left(\mathrm{W}_{1}\right)$ & $1.4 \mathrm{~mm}$ \\
Length of the slots $\left(\mathrm{L}_{1}\right)$ & $14.2 \mathrm{~mm}$ \\
Width of the non-radiating edges $\left(\mathrm{S}_{1}\right)$ & $1.4 \mathrm{~mm}$ \\
Thickness of the Microstrip Patch $(\mathrm{Mt})$ & $0.1 \mathrm{~mm}$ \\
Gap between transmission line and patch $(\mathrm{Gpf})$ & $1 \mathrm{~mm}$ \\
\hline
\end{tabular}

\section{Simulation Results of Dual Band Antenna}

The various parameters like Return loss, Voltage Standing Wave Ratio (VSWR) Smith chart, Directivity and Gain of this antenna are simulated using CST microwave studio 2009 as discussed in the following subsections.

\subsection{Return loss, VSWR and Smith chart}

The return loss (RL) is the parameter which indicates the amount of power is lost in the load and does not return as a reflection. As already known, waves are reflected leading to the formation of standing waves when the transmitter and antenna impedance do not match. Hence the RL is the parameter similar to VSWR to indicate how well the matching between the transmitter and the antenna has taken place. Fig.2. Shows return loss of the designed rectangular Microstrip Antenna. Our designed antenna gives the return losses $-21.25 \mathrm{~dB}$ and $-27.5 \mathrm{~dB}$ at the resonance frequencies of $2.45 \mathrm{GHz}$ and $4.1 \mathrm{GHz}$, respectively. As we know that the acceptable value of return loss is less than $-10 \mathrm{~dB}$, thus the results show that the designed antenna is perfectly matched and the power loss is minimum so the gain and efficiency is maximum [3]. And if we go through the below and upper ranges of these two resonance frequencies the antenna does not provides good impedance matching and hence the radiation from the antenna will be minimum. It also gives a bandwidth of approximately $90 \mathrm{MHz}$ at $2.45 \mathrm{GHz}$ and $115 \mathrm{MHz}$ at $4.1 \mathrm{GHz}$ which are applicable for Wireless Local Area Network.

The voltage standing wave ratio (VSWR) is another parameter defined for antenna which determines that how well the antenna is matched. For a good antenna the value of VSWR is found less than or equal to 2 for practical antennas. Fig.3. and Fig.3. show the VSWR of the designed dual band rectangular microstrip patch antenna. From figures, it is clear that a VSWR of 1.3883 is found at the resonant frequency $2.45 \mathrm{GHz}$ and that 
of 1.0825 is found at the resonant frequency $4.1 \mathrm{GHz}$, which is below 2 . Hence our designed antenna is perfectly matched with minimum loss.

The smith chart of our designed antenna is shown in Fig.4. The figure shows that at resonant frequency 2.45 $\mathrm{GHz}$ the response locus lies above the real axis, hence it is inductive dominating and at resonant frequency 4.1 $\mathrm{GHz}$ the response locus lies below the real axis, hence it is capacitive dominating. The good impedance response is obtained by adding a series capacitor at the input with a reactance $-\mathrm{j} 50$ for $2.45 \mathrm{GHz}$ frequecy and by adding a shunt capacitor at the input with a reactance $-\mathrm{j} 50$ for $4.1 \mathrm{GHz}$ frequecy.From this chart it is clear that at both frequencies the impedance of the designed dual band antenna is 49 ohms which is approximately equal to the desired value of $50 \mathrm{ohms}$, indicating the minimum loss.

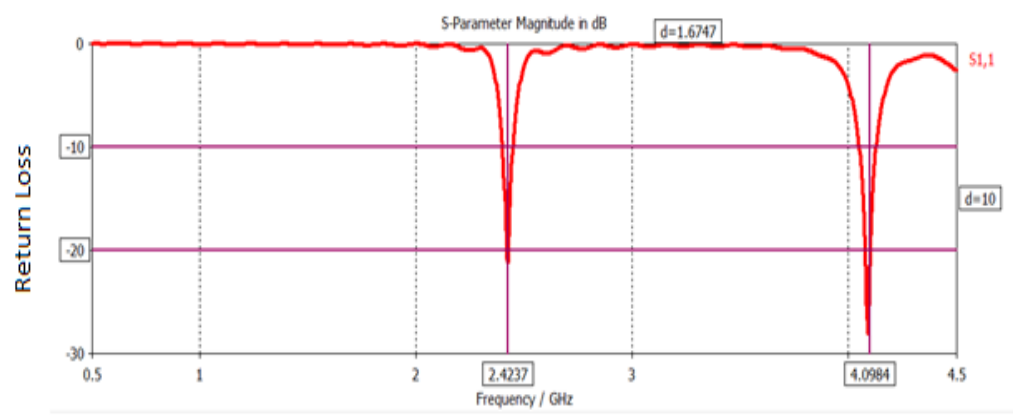

Fig.2. Simulated return losses of dual band MSA at $2.45 \mathrm{GHz}$ and $4.1 \mathrm{GHz}$

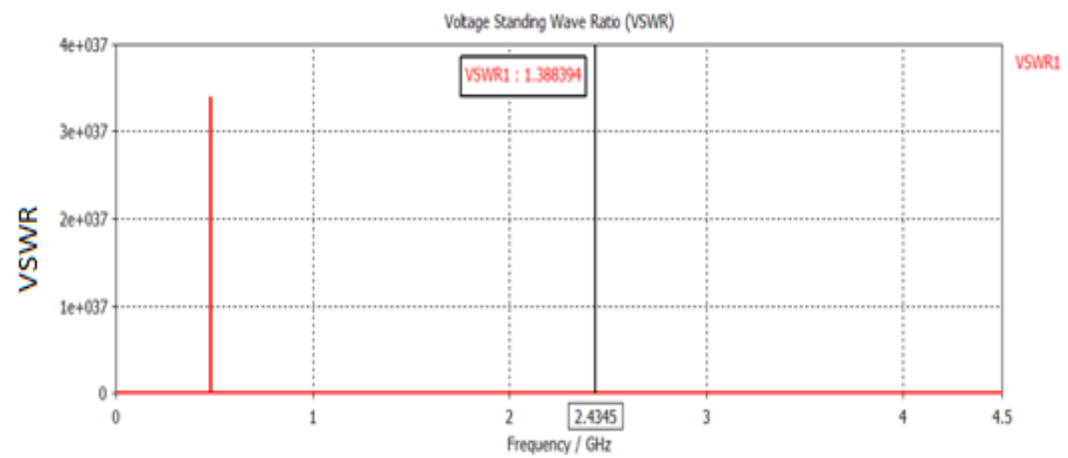

(a)

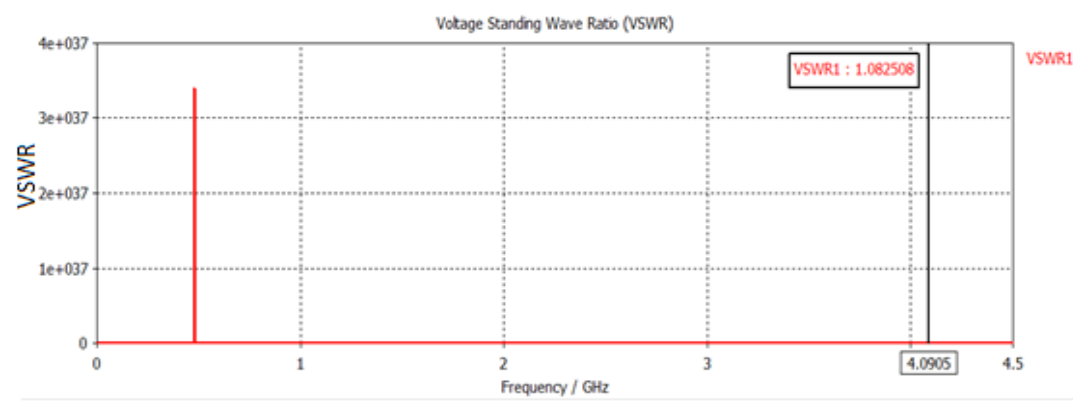

(b)

Fig.3. The VSWR of dual band MSA at (a) $2.45 \mathrm{GHz}$; (b) $4.1 \mathrm{GHz}$ 


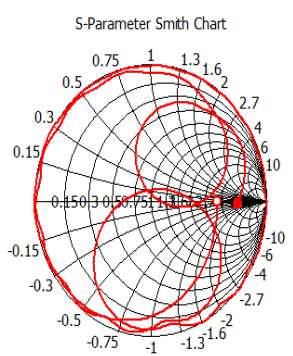

$51,1(49 \mathrm{ohm})$

Fig.4. Smith Chart of dual band MSA at $2.45 \mathrm{GHz}$ and $4.1 \mathrm{GHz}$

\subsection{Directivity and Gain}

The simulated results [3] of the directivity at 2.45 GHZ and 4.1 GHZ are shown in Fig.5. and Fig.6. respectively. The figure shows that it is a high directional antenna. From 2D and 3D pattern it is clear that the main lobe magnitudes are found $7.2 \mathrm{dBi}$ in positive $\mathrm{Z}$ direction with angular width of $75.7 \mathrm{deg}$ and $6.3 \mathrm{dBi}$ at an angle 49.0deg from positive $\mathrm{Z}$ direction with angular width of $68.5 \mathrm{deg}$ at the resonant frequencies of 2.45 $\mathrm{GHz}$ and $4.1 \mathrm{GHz}$ respectively which agree well with the previous results.

The gains of the designed dual band antenna are given in Fig.7. and Fig.8. Since the graph represents that it is a high directional antenna so the gain of the antenna is high at a specific direction. The gains of the designed antenna are $6.698 \mathrm{~dB}$ and $6.797 \mathrm{~dB}$ at $2.45 \mathrm{GHz}$ and $4.1 \mathrm{GHz}$ frequencies, respectively. From 2D pattern it is also clear that the main lobe magnitudes are $6.7 \mathrm{~dB}$ and $6.8 \mathrm{~dB}$ and the directions of the main lobes are $0.0 \mathrm{deg}$. and $53 \mathrm{deg}$. with angular widths $75.7 \mathrm{deg}$. and $66.7 \mathrm{deg}$. at $2.45 \mathrm{GHz}$ and $4.1 \mathrm{GHz}$ frequencies, respectively which agrees well with the previous results.

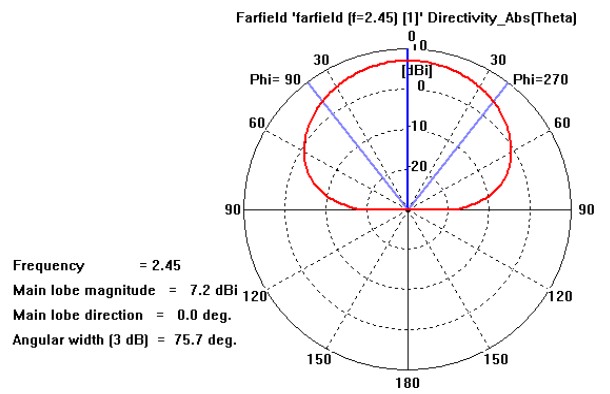

(a)

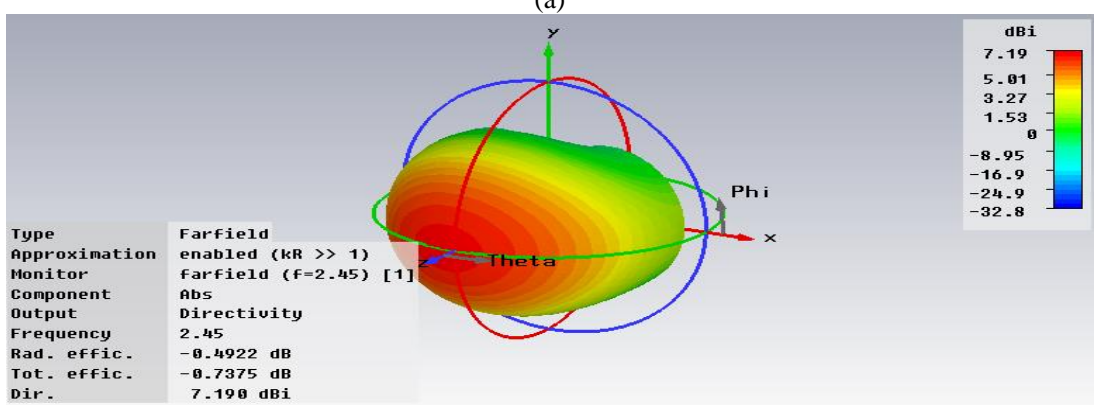

(b)

Fig.5. Directivity of dual band MSA at 2.45GHz (a) 2D pattern; (b) 3D pattern 


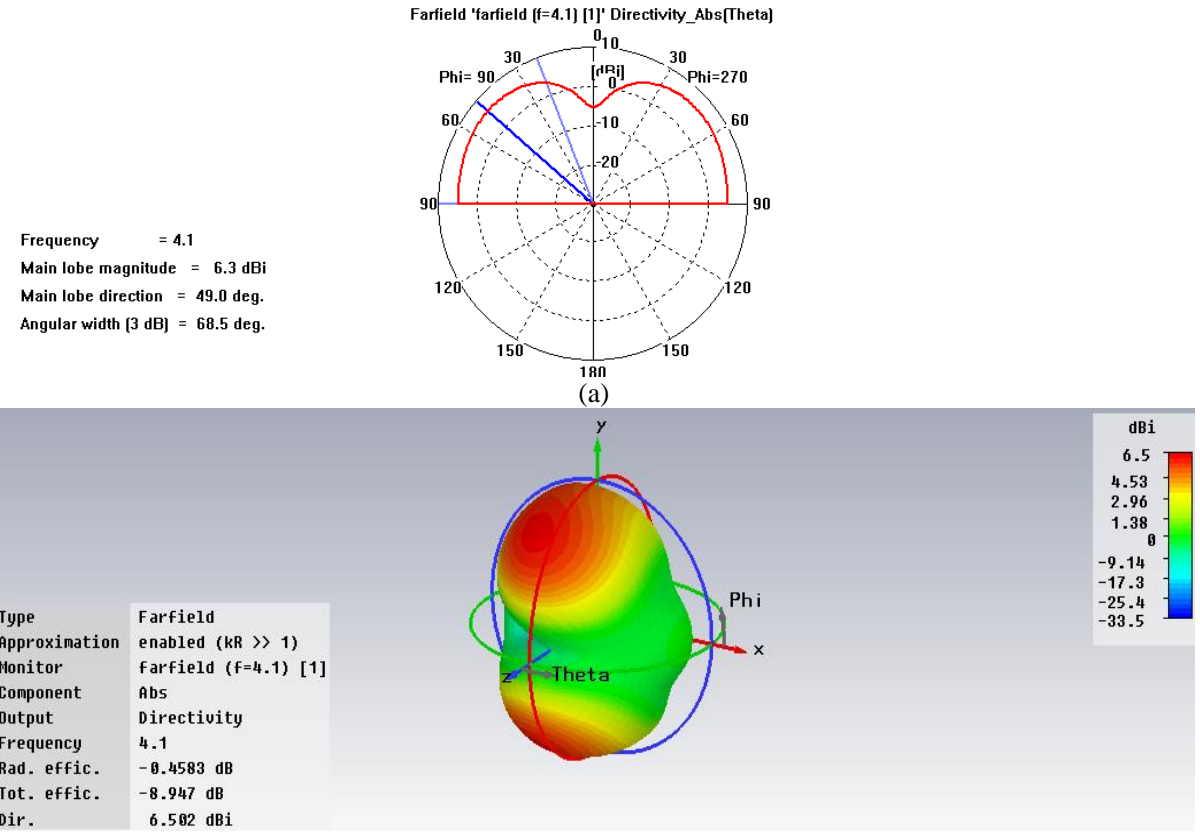

(b)

Fig.6. Directivity of dual band MSA at $4.1 \mathrm{GHz}$ (a) 2D pattern; (b) 3D pattern

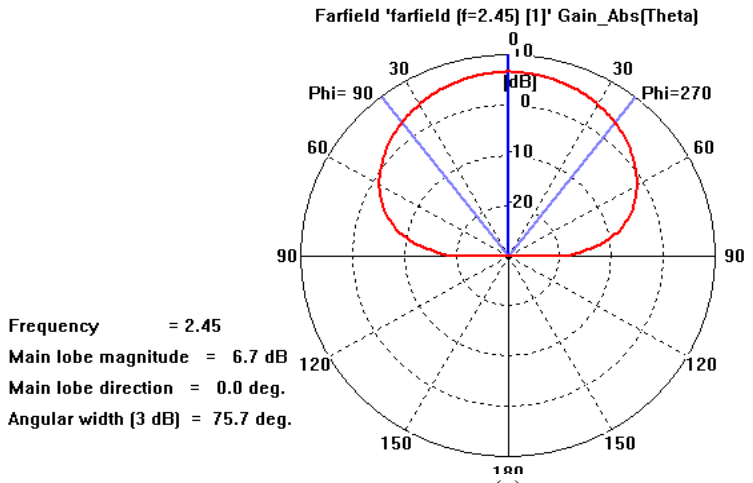

(a)

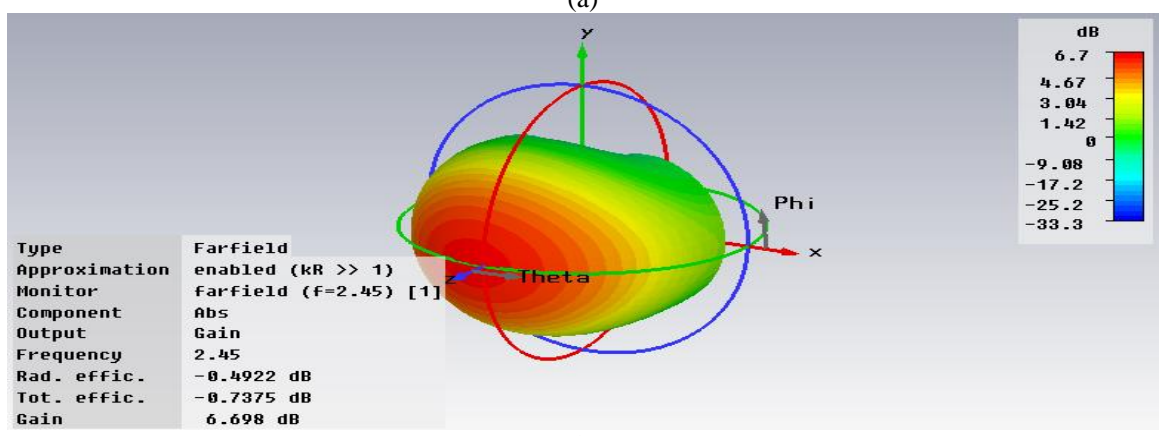

(b)

Fig.7. Gain of dual band MSA at $2.45 \mathrm{GHz}$ (a) 2D pattern; (b) 3D pattern 

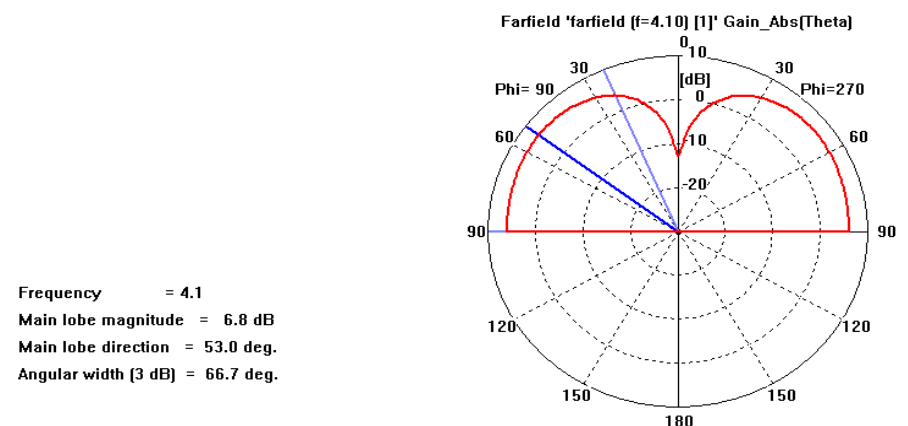

(a)

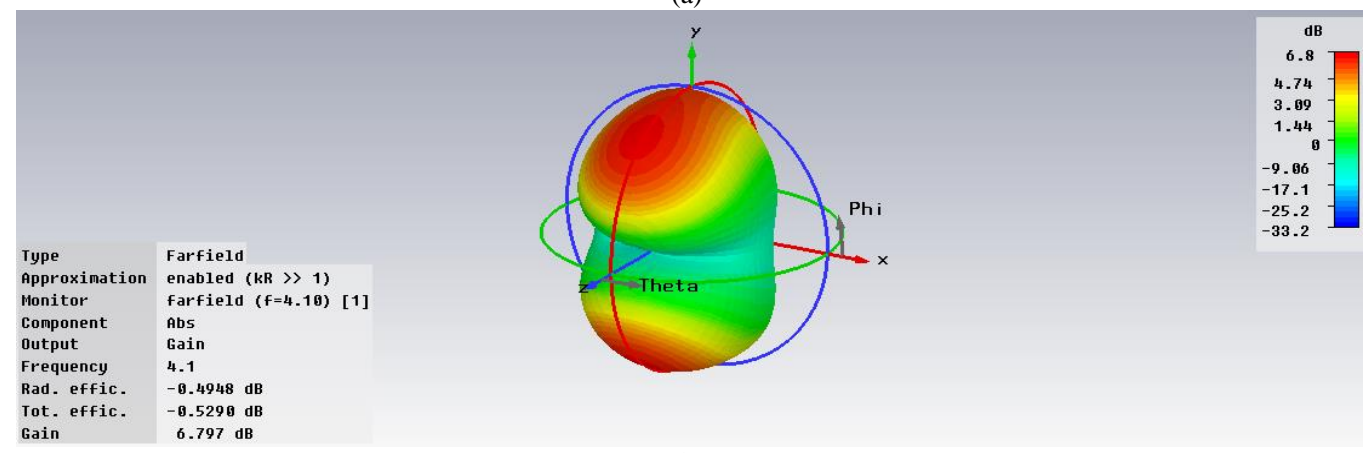

(b)

Fig.8. Gain of dual band MSA at 4.1GHz (a) 2D pattern; (b) 3D pattern

\section{Summary of the Results}

The results of the dual band rectangular microstrip antenna operating at $2.45 \mathrm{GHz}$ and $4.1 \mathrm{GHz}$ are summarized in table 2 .

Table 2. Output parameters of the dual band MSA resonating at $2.45 \mathrm{GHz}$ and $4.1 \mathrm{GHz}$ frequencies

\begin{tabular}{llllll}
\hline Resonating frequency fr $(\mathrm{GHz})$ & Return loss $(\mathrm{dB})$ & Bandwidth $(\mathrm{MHz})$ & VSWR & Directivity $(\mathrm{dB})$ & Gain $(\mathrm{dB})$ \\
\hline 2.45 & -21.25 & 90 & 1.3846 & 7.190 & 6.698 \\
4.1 & -27.5 & 115 & 1.082 & 6.502 & 6.797 \\
\hline
\end{tabular}

The above table reflects that the designed antenna provides good impedance matching at two resonance frequencies of $2.45 \mathrm{GHz}$ and $4.1 \mathrm{GHz}$ with return losses of $-21.25 \mathrm{~dB}$ and $-27.5 \mathrm{~dB}$ respectively. So it is a dual band antenna with high directivities of $7.190 \mathrm{~dB}$ and $6.052 \mathrm{~dB}$ at these two resonance frequencies respectively. Due to the high directivity the gains of our designed antenna are higher.

\section{Conclusions}

In this paper, initially we have looked on the design and simulation of single band rectangular microstrip patch antenna and then extend it to dual band rectangular microstrip patch antenna. Here the various parameters like return loss, impedance, VSWR, directivity, gain, bandwidth and operating frequency are studied and also the effects of physical parametric on the performance of the designed antenna are studied. The designed dual 
band antenna shows good impedance matching of approximately 49 ohm's. Also it provides good gain and efficiency at the resonant frequencies of $2.45 \mathrm{GHz}$ and $4.41 \mathrm{GHZ}$ which indicate that the designed antenna can be used for various applications like RADAR, Bluetooth, Biomedical instruments etc.

\section{Acknowledgements}

We would like to thank all concerned with the AECE department for their all-out effort to support us for completing this research.

\section{References}

[1] Shagun Maheshwari, Priyanka Jain, Archana Agarwal, "CPW-fed Wideband Antenna with U-shaped Ground Plane," I.J. Wireless and Microwave Technologies (IJWMT). Volume 5, November 2014.

[2] Sheikh Dobir Hossain, K M Abdus Sobahan, Md. Khalid Hossain, Md. Khalid Hossain Jewel, Rebeka Sultana, Md. Al Amin, "A Linear Polarized Coaxial Feeding Dual Band Circular Microstrip Patch Antenna for WLAN Applications,” I.J. Wireless and Microwave Technologies (IJWMT). Vol. 1, 2016.

[3] C.A. Balanis, Antenna Theory: Analysis and Design, Third Edition, ISBN 0-471-66782-X, Copyright 2005 John Wiley \& Sons, Inc.

[4] D.M. Pozar, "Microstrip Antennas," Proc. IEEE, Vol. 80, No. 1, pp. 79-81, January 1992.

[5] C.M. Krowne, "Cylindrical-Rectangular Microstrip Antenna," IEEE Trans. Antennas Propagat., Vol. AP31, No. 1, pp. 194-199, January 1983.

[6] I. Lier and K. R. Jakobsen, "Rectangular Microstrip Patch Antennas with Infinite and Finite Ground-Plane Dimensions,” IEEE Trans. Antennas Propagat., Vol. AP-31, No. 6, pp. 978-984, November 1983.

[7] S.A. Long and M.D. Walton, "A Dual-Frequency Stacked Circular-Disc Antenna," IEEE Trans. Antennas Propagat., Vol. AP-27, No. 2, pp. 270-273, March 1979.

[8] Neha Parmar et al. "Review of Microstrip Patch Antenna for WLAN and WiMAX Application," Int. Journal of Engineering Research and Applications ISSN: 2248-9622, Vol. 4, Issue 1(Version 1), January 2014, pp.168-171.

[9] M.D. Van Wyk and K.D. Palmer, "Bandwidth enhancement of microstrip patch antennas using coupled lines," IEE Electronics Letters, Vol.37, No.13, pp.806-807, 2001.

[10] N. Chiba, T. Amano and H. Iwasaki, "Dual-frequency planar antenna for handsets," IEE Electronics Letters, Vol.34, No.25, 1998.

[11] C.L. Mak, K.M. Luk, K.F. Lee, and Y.L. Chow, "Experimental Study of a Microstrip Patch Antenna with an L-Shaped Probe," IEEE Transactions on antennas and propagation, Vo.48, No.5, May 2000.

[12] Kin-Fai Tong, Kwai-Man Luk, Kai-Fong Lee, and Richard Q. Lee, “ A broadband U slot rectangular patch antenna on a microwave substrate," IEEE Transactions on antennas and propagation, Vol.48, No.6, pp. 954-961, 2000.

[13] Y.X. Guo, K.M. Luk and K.F. Lee, "U-slot circular patch antennas with L-probe feeding," IEE Electronics Letters, Vol.35, No.20, pp. 1694-1695, 1999.

[14] Carver, Keith R., and James Mink. "Microstrip antenna technology," Antennas and Propagation, IEEE Transactions , pp 2-24, Feb 1981.

[15] C.A. Balanis, Advanced Engineering Electromagnetics, JohnWiley \& Sons, New York, 1989. 


\section{Authors' Profiles}

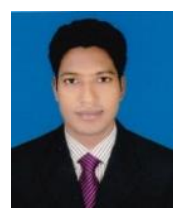

Mr. Sheikh Dobir Hossain is working as a Lecturer in the dept. of Physics at Jessore University of Science and Technology, Jessore-7408, Bangladesh. He holds the degree of B.Sc \& M.Sc in Applied Physics, Electronics \& Communication Engineering from Islamic University, Kushtia7003, Bangladesh. The fields of his research interest are wireless antenna design, wireless communication, and material science.

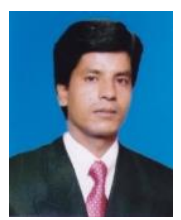

Mr. K. M. Abdus Sobahan received his PhD degree from the Inha University, South Korea. He received his Bachelor's and Master's degree from the dept. of Applied Physics \& ElectronicsUniversity of Rajshahi, Rajshahi-6205, Bangladesh. Currently he is working as a professor in the dept. of Applied Physics, Electronics \& Communication Engineering of Islamic University, Kushtia-7003, Bangladesh.

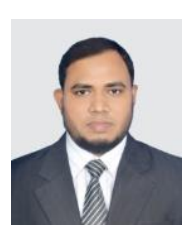

papers.

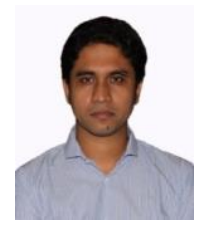

Mr. Md. Masud Ahamed Akash received his Bachelor's and Master's degree from the dept. of Applied Physics, Electronics \& Communication Engineering of Islamic University, Kushtia7003, Bangladesh. Now he is working as a System Engineer at Apple Communication Limited .His research interest includes Ad-hoc wireless communication, cellular mobile communication and optical fiber communication.

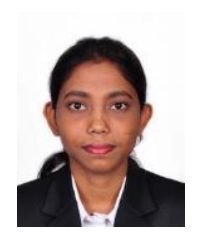

Ms. Rebeka Sultana has been received B.Sc (Eng.) degree in Computer Science \& Engineering (CSE) from University of Rajshahi, Rajshahi-6205, Bangladesh. Currently she is a MS student of the Department of Electrical \& Electronic Engineering (EEE), Shizuoka University, Japan. Her current research interest are computer vision, pattern recognition, image processing, artificial intelligence, signal processing, digital image processing, automatic control, wireless antenna design and wireless communication.

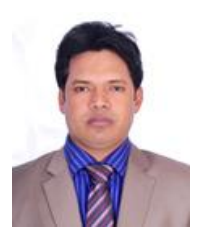

Mr. Md. Masum Billah received his B.Sc (Hons) and M.Sc degree in Physics from University of Dhaka, Bangladesh. Recently he is working as a Lecturer in the department of Physics at Jessorec University of Science and Technology, Jessore-7408, Bangladesh. His research Interest fields are Biomedical Physics, Microelectronics, Laser Physics, High Energy Particle Physics and mobile communication. 